\title{
Rights, Commons, and Social Capital: The Role of Cooperation in an Italian Agri-Food Supply Chain
}

\author{
Enrico Giovannetti * (D), Paola Bertolini * and Margherita Russo (1) \\ Centro Analisi Politiche Pubbliche (CAPP), Dipartimento di Economia Marco Biagi, Università degli studi di \\ Modena e Reggio Emilia UNIMORE, 41121 Modena, Italy; margherita.russo@unimore.it \\ * Correspondence: enrico.giovannetti@unimore.it (E.G.); paola.bertolini@unimore.it (P.B.)
}

\section{check for}

updates

Citation: Giovannetti, E.; Bertolini, P.; Russo, M. Rights, Commons, and Social Capital: The Role of Cooperation in an Italian Agri-Food Supply Chain. Sustainability 2021, 13, 12161. https://doi.org/10.3390/ su132112161

Academic Editors: Elena Pisani, Julien Vanhulst and Stefano Micheletti

Received: 20 August 2021 Accepted: 30 October 2021 Published: 4 November 2021

Publisher's Note: MDPI stays neutral with regard to jurisdictional claims in published maps and institutional affiliations.

Copyright: (c) 2021 by the authors. Licensee MDPI, Basel, Switzerland. This article is an open access article distributed under the terms and conditions of the Creative Commons Attribution (CC BY) license (https:/ / creativecommons.org/licenses/by/ $4.0 /)$.
Abstract: The paper discusses the relationship between Commons, Social Capital, and sustainability in terms of resources used, tools available, and goals to be achieved. The conceptual framework differs from the traditional one, which considers Commons and Social Capital as different resources. The paper considers Commons and Social Capital as homogeneous assets defined by the rights related to the access, use, and reproduction of collective resources, material or immaterial, which are essential to reduce the difference between private and social costs in the economic processes. This approach derives from a definition of sustainability as a private and social responsibility in reproducing all the resources used in the life processes, minimizing the waste caused by their exhaustion and loss of fertility. The paper refers to the model of Commons by the school of Elinor Ostrom to explain the nature and role of Social Capital and to observe it in different units of analysis, with particular attention to the forms of cooperative enterprise. The last part of the work outlines field research on the Parmigiano Reggiano supply chain as a natural laboratory to test the theoretical hypotheses.

Keywords: sustainability; commons; social capital; cooperative; agri-food supply chain; parmesan cheese district

\section{Introduction}

The paper seeks to highlight theoretical and empirical evidence that demonstrates the link between Social Capital (SC) production and resource regeneration, which is considered the main aspect of sustainability. The case of the Parmigiano Reggiano supply chain analyzed in the paper is an important natural laboratory for testing this hypothesis.

The definitions of sustainability present in the literature are numerous, often ambiguous, and sometimes contradictory [1,2]. To analyze the relationship between sustainability and social capital, it is useful to collect the different approaches into three large groups, of which only one seems logically sustainable and compatible with the concept of SC.

The first one is based on the search for an optimal balance of the needs and consumption of the current generation versus those of future generations. The second approach focuses on the efficiency of the circular process production-consumption-(re)production. The last one concerns the degree of conservation of the fertility of the resources in the process of use-reproduction of the resources themselves. If natural resources, materials, and human capabilities were always abundant, the three approaches would not lead to different conclusions from the classical ones of economic efficiency.

In the face of the growing scarcity of raw materials and environmental degradation and the increase in inequalities, the first approach to sustainability shows all its logical inconsistency: today, the future generations cannot express an effective demand for the resources necessary to cover their future needs; therefore, there is no mechanism that can determine the real value of scarcity. Will the legacy of SC-such as shared norms, values, trusts, attitudes, and beliefs, which are valid for a generation-still be able to help the new generations to face the different challenges, or will they represent a serious obstacle to facing the new challenges in an innovative way? According to Diamond [3] 
and Acemoglou et al. [4], conservative institutions-locked in identity rules, foreseeing the future as a projection of the past-are among the main causes of the crisis and extinction of ancient civilizations.

The second approach, which considers the efficiency of the circular economy, appears much more robust, with explicit attention to minimizing waste and environmental damage. In this vision, an engineering perspective of optimization prevails, with the search for best practices supposing positive effects of innovation [5]. However, the effectiveness of this approach is linked to the different interests of the agents and to the definition of the "limits" of the responsibilities of the decision-makers. Therefore, if the targets are visible, the expected behaviors of the different actors are less clear: who should take care of the sustainability of all systems going beyond the boundaries of the individual interests, why, and how? How will shared norms, values, trusts, attitudes, and beliefs help overcome the "NIMBY syndrome" of opulent societies that want to offload the cost of their waste onto others? This approach lacks indications of the social actions to bridge the gap between private and collective interests.

The last definition of sustainability adopted in the paper is focused on the idea that the reproduction of the resources' fertility must be a responsibility and a commitment of those who use them, directly or indirectly. In other words, we consider a sustainable system capable of reproducing and regenerating all the resources used in the economic processes - with the respect to the natural time needed for their regeneration-in order to maintain or increase the capacities/fertility of the resources themselves, supporting (minimizing) the social costs deriving from their use (capacity loss, waste, social and environmental decay) [6].

According to our definition, the classical concept of Paretian efficiency of maximizing the private profit to pursue efficiency is neither a sufficient nor necessary condition to guarantee the sustainability of a socio-economic process. From a theoretical point of view, the resources cannot be considered "given", both because many of them are exhaustible, and because all of them must be continuously regenerated to maintain their economic fertility. Some regeneration processes are carried out during the usual activity (e.g., the amortization of physical capital), while other ones may be incompletely or not regenerated, especially when they are considered "external" to the process of production. In this context, the classic economic objective-of minimizing costs and maximizing revenues—may represent a rational behavior for some agents, but it is neither a sufficient nor necessary condition to guarantee a solution to the social dilemma of reducing the progressive divergence between private and social costs [6]. In terms of the new institutional economy, the divergence between private and social costs will not necessarily be resolved by market or hierarchical coordination. On the contrary, it is very likely that without a social action, the search for a sustainable solution will not even be addressed [7]. The construction and use of SC must be considered an important attempt to resolve/mitigate the recalled divergence. Therefore, the paper seeks to highlight some logical links and empirical evidence able to testify the link between the SC production and the resource regeneration. The case of the Parmigiano Reggiano supply chain is an important natural laboratory for testing this hypothesis

Based on the research question, the paper is structured in five parts: after this introduction (Section 1), Section 2 presents the theoretical background, Section 3 specifies methods and empirical materials, and Section 4 discusses the results of the empirical research. Finally, Section 5 proposes some concluding remarks. More specifically, in Section 2, Section 2.1 addresses the issue of a new definition of the SC as a set of rights; Section 2.2 discusses how the proposed definition is congruent with the concept of "Commons" according to the model of Elinor Ostrom (MO); in Section 2.3, the analysis moves from a meso-economic to a micro-economic plan, discussing how the companies belonging to the cooperative movement play a relevant role in the construction of SC; Section 2.4 focuses on a critical discussion of the presumed negative effects of SC—the so-called "dark side" of the SC-which the literature considers a not negligible aspect, especially when the unit of analysis is the business organization [8]. Section 3 (Sections 3.1 and 3.2) describes the 
reasons of interest of the case study on the Parmigiano Reggiano (PR) cheese supply chain, and Section 4 (Section 4.1, Section 4.2, Section 4.3) presents the results of in-depth research, where the role of the SC, deriving by cooperation, is relevant to increase the sustainability and resilience of the production chain and of the entire eco-social local system, even in the economic fragile areas.

\section{Theoretical Background}

\subsection{Social Capital as a Set of Rights}

The huge literature on SC seems to agree in dividing the contributions into two main strands, structuralist and culturalist (cognitive) vision $[7,9,10]$. The first strand considers SC as a "hardware", a "resource" built on consolidated roles, social networks, and other social structures. The second one focuses its attention on the collective cognitive "resources", such as shared norms, values, trust, attitudes, and beliefs: SC is like a software. Both strands refer to SC as a resource-existing or used-but none of them defines what is the "nature" of SC, avoiding a tautological definition: using again ICT language, they miss the explanation of SC as "operating system". As a proof of this lack, there is the misleading use of the indicators to measure SC: no matter what classification they belong to, most of them may be used in a contradictory way to support the existence of SC or, in the opposite direction, as a counterfactual, showing the dark side of SC.

The definition of SC, and therefore of its measure, is a well-known issue. The common core of the various criticisms is the association of the two terms "capital" and "social", which are considered antithetical, generating an oxymoron more dangerous than useful for deepening the theory or rigorously using in the empirical research [11,12]. Therefore, the standard theory considers the use of the term "social capital" improper and misleading. Moreover-and even more important - the conceptual ambiguity of the concept and definition of SC stands as a serious obstacle to the multidisciplinary dialogue [9] (p. 7). At the empirical level, some contradictions are evident, as shown in the following examples:

1. For any indicator of SC, it is possible to find positive or counterfactual negative effects (e.g., social cohesion vs. mafia; belief vs. superstition; etc.);

2. The role of the relationships among agents, spontaneous or induced by the context, is ambiguous because of the circularity between the production and consumption of SC that makes never clear whether these elements are the solution or part of the problem. For example, it is not clear how to measure SC when the unit of analysis is modified, shifting from the enterprise to the territory [13]. Is SC engendered by the action of the companies or, on the contrary, does the presence of SC determine a specific business/institutions behavior?

3. More specifically, the literature shows that when dealing with a specific issue such as local development-as in the case of this paper-the role of cooperative enterprises and of cooperation is a basic problem in the definition of SC.

In the paper, we propose the following definition: $S C$ is the set of all the economic material or intangible assets, resulting from the collective decisions for producing public goods, toll goods, and common goods. Therefore, it is a set of goods for which the right of access and enjoyment is not governed exclusively by individual choices of use, exclusion, and transfer. These rights define the resource SC as the result of collective choices of access, use, and reproduction of non-private economic assets - no matter if tangible or intangible - by the application of rules, which are distinctive of the specific economic process. The measure of the productivity of SC is its contribution to increasing the sustainability of the ecological-social system that uses it.

The indication by R. Coase is the first and most effective exemplification of the core of the theoretical problem: the inadequacy of the term SC being understood as the "quantity" of a resource; in general, this a problem no different from the ambiguity of measuring any form of capital as a given factor. 
"A ... reason for the failure to develop a theory adequate to handle the problem [ ... ] stems from a faulty concept of a factor of production. This is usually thought of as a physical entity which the businessman acquires and uses (an acre of land, a ton of fertilizer) instead of as a right to perform certain (physical) actions. We may speak of a person owning land and using it as a factor of production but what the landowner in fact possesses is the right to carry out a circumscribed list of actions. [... ]. This does not come about simply because of Government regulation. It would be equally true under the common law. In fact, it would be true under any system of law. A system in which the rights of individuals were unlimited would be one in which there were no rights to acquire." [14] (p. 43-44).

The change of perspective on the nature of SC-from a given resource to a set of rights and duties on non-private assets that generate the resource itself-is not at all obvious, but it may be fundamental in the discussion on SC and its role in the resilience of a business or a specific area. In this regard, according to the empirical part of the paper, there are examples of investments in SC deriving by a collective decision to implement the quality system of the production chain, to change the rules for selling the product, and to implement a digital platform to manage e-commerce [15-17]. All the recalled examples are specific cases of construction of SC by means of SC, where the investment in SC is activated reshaping (acquisition, transfer, abolition, redefinition) all the existing rights-private and non-private, legal, or customary - that allow economic and social processes to be carried out over time.

The transition from a vision of the SC as a "resource" to a different idea of SC as a set of rights and duties allows overcoming the criticisms addressed to the logical coherence and economic consistency of the concept of SC, including the misleading debate on the "dark side", which we will address later.

\subsection{The Sustainability of the "Commons" in the Elinor Ostrom's Model}

The discussion on the so-called "Tragedy of the Commons" has a path that runs in parallel to the debate about the nature and the measure of SC. From the famous work of Garret Hardin [18] to the innovative contribution of Ostrom [19-22] and her research team $[23,24]$, the debate on this issue was mainly focused on the idea that water, marine biomass, forests, wild animals, etc., existing in nature, had to be considered a stock of economic "resources", no differently from iron, territory or fossil deposits from which humanity has drawn throughout its history. In the traditional economic theory, all these resources are resumed in the category "Land", whose use/value is regulated by the exercise of the private rights and, therefore, by the market. In this vision, if a specific factor is "abundant", its economic value will be zero and, if it is scarce, it will be determined by the market thanks to the action of supply and demand.

According to the standard economic culture, the "Commons" are engendered by a lack of a clear and properly established rights of private property: therefore, they are not excludable but rivals in consumption. As it is generally known, a significant economic problem arises when a free access to the "resource" causes a divergence between private and social costs: each agent will have an opportunistic convenience in using most of the resource to prevent another "opportunistic" agent from doing the same still to a greater extent. In a world where the homo economicus is dominant among the species, common resources are expected to be exhausted through an exploitation that does not respect the limited nature of the deposits and/or the natural times of the reproduction in the case of the living species. 
Given the Commons, to avoid the "tragedy" of their destruction by a super exploitation, there have been two opposite policy proposals to make the use of these factors sustainable: the need for state intervention to protect resources with rules and constraints for their use versus the need to better define the private rights of exploitation allowing a full internalization of costs and a more rational self-regulation in the private use: that is, the Illuminist State vs. Perfect Market [19] (p. 9).

Ostrom's work, starting from the contributions of the 1960s, is a theoretical and empirical navigation between the ideology of the Omnipotent State and the indisputable superiority of Private Efficiency. In her forty years of contributions-with the acknowledgement of the Nobel Prize-her relevant field research aimed to elaborate all the possible solutions to the main "social dilemma" of sustainability: to find the balance between short-term private interest and long-term social advantages. In particular, she focused on the selection of the circumstances making possible a collective, cooperative, and sustainable management of common resources, which are reproduced and available to the community in the long term. In this perspective, the process of definition and reproduction over time of such circumstances is the nature of the "common good" and corresponds to the asset of Social Capital embedded in the ecological-social system studied. In her empirical approach, no less important is the search for counterfactuals: first, the study of the reasons for the possible failures and, therefore, the dissolution of the SC produced and used previously. Moreover, the research was supported by the verification in the behavioral economics laboratories and by the meta-analysis of the collected material [24]. For instance, anticipating the empirical example that follows, the disciplinary of Parmigiano Reggiano is a Commons — and an SC asset—of the system and constitutes a prerequisite, a tool, and an outcome of the functioning of the process. Its economic role as SC is no less important in the supply chain than a private capital asset (e.g., a cow or a milk tank).

In the model of Ostrom (MO) and her collaborators [23] (Figure 1), Commons/SC production depends on the simultaneous realization of eight conditions A.1-A.8, which regulate the access and reproduction of the common resources. In more detail, the functioning and resilience of an ecological-social system depends on the success in maintaining/changing the equilibrium conditions of two groups of forces: the different criticalities produced by the relationships between internal stakeholders (arrows 1-6) must be contrasted with the respect of conditions A.1-A.6; the best possible internalization of shocks that originate outside the system (arrows 7 and 8 ) is easier if conditions A.7 and A.8 occur. Operationally, an ecological-social system is a process that is carried out by continuously counteracting the internal (B.3 and B.4) and external threats (B.1, B.2, B.5).

The framework in the figure never describes "events" but socio-economic processes that are historically determined [20]. In other words, the units investigated (Commons or SC, no matter if a territory, a natural resource, a company, a quality system, etc.) must be defined by an interval of time and by an "institutional" boundary separating what is relevant within the observed process from what belongs to the context in which the process itself takes place [25]. It is important to note the convergency of results with other analyses [4] also from disciplines other than economics and sociology [1].

The model just described will be used in the description of the case analyzed in Section 3. 


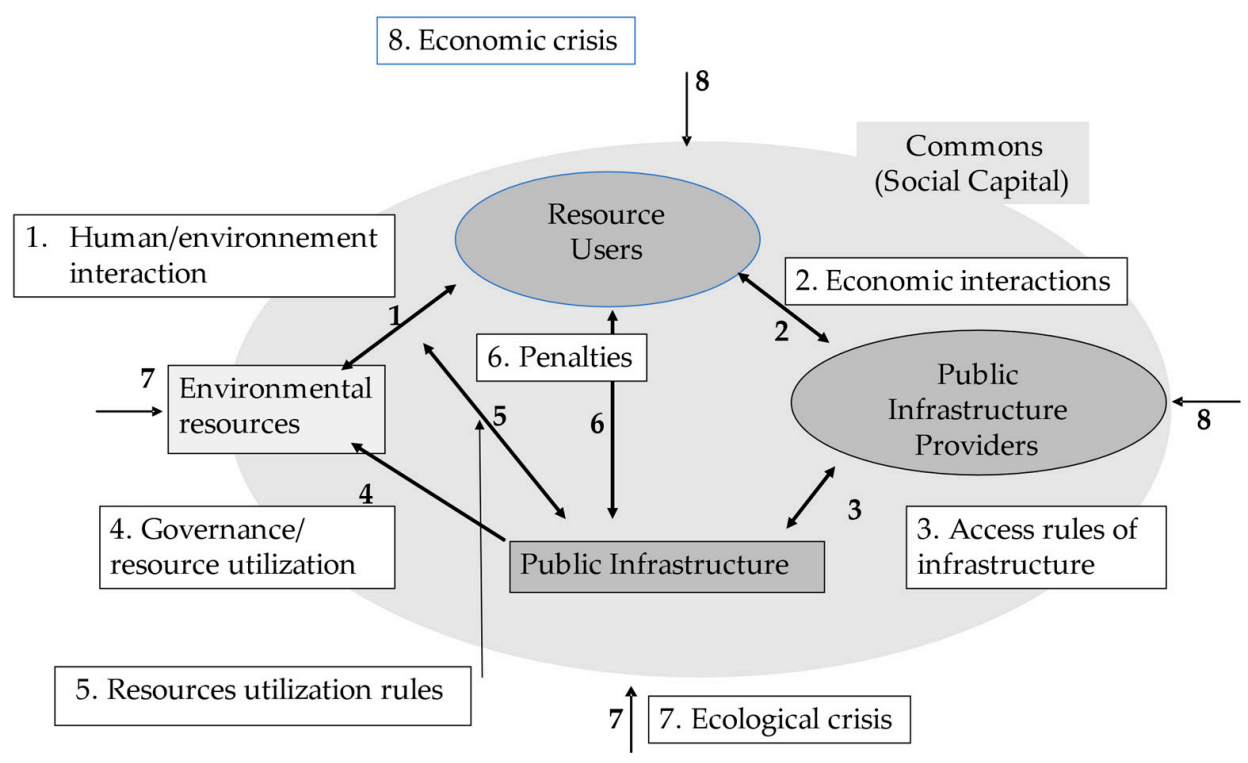

(A) Necessary condition for Common's Sustainability and Resilience

1. Clearly defined boundaries (effective exclusion of external unentitled parties);

2. Rules regarding the appropriation and provision of common resources are adapted to local conditions;

3. Collective-choice arrangements allow most resource appropriators to participate in the decision-making process;

4. Effective monitoring by monitors who are part of or accountable to the appropriators;

5. There is a scale of graduated sanctions for resource appropriators who violate community rules;

6. Mechanisms of conflict resolution are cheap and of easy access;

7. The self-determination of the community is recognized by higher-level authorities;

8. In the case of larger common-pool resources: organization in the form of multiple layers of nested enterprises, with small local Common Pooled Resources at the base level.

(B) Threats to Commons and Social Capital

1. Rapid exogenous changes

- Rapid changes in technology or population numbers can become a challenge to effective governance of the commons.

2. Translation failures

- Informal arrangements can be translated into official rules. For example, when writing the bylaws of a homeowner's association, the rules are often based on informal practices. Over time, the reasons why some formal rules are written in the books may be lost, which may lead to problems.

3. Blueprint thinking

- The fact that some rules work out well in one action situation does not mean that those same rules will work well for other situations.

4. Corruption and rent seeking

- When individuals in power have the opportunity to allocate resources, there is always the possibility of corruption.

5. Lack of large-scale supportive institutions

- Small-scale communities can be very effective in self-organizing and sustaining their shared resources but will eventually experience challenges in the long term if they do not have the support of larger-scale institutions.

Figure 1. Commons and Social Capital: the structure of the model; (A) the necessary conditions for sustainability; (B) threats to resilience. Source: $[20,23]$.

\subsection{Social Capital and Cooperative Networks}

The literature on the nature, role, limits, and destinies of the cooperative enterpriseand later the social enterprises - has faced over time some critical problems similar to those of SC and the Commons, mentioned above, even if the debate on cooperation is independent and older. The cooperatives and the cooperative movement are an important laboratory for a counterfactual analysis of the organizational models of possible forms of enterprise.

With origins tracing back to the foundation of a small shop in Rochdale (UK) in 1844 , the modern cooperative firm constitutes an organizational reaction to the vast social costs engendered by the first industrial revolution $[7,26,27]$. The cooperative organization 
transitioned from a utopian form of enterprise into a modern organizational structure with the adhesion to and respect for seven rules (Table 1). This mutual form of enterprise, which jointly produces goods, services, and SCs, shows that the boundaries of the firm do not coincide with only property rights of the private capital. In line with our defining of sustainability, it can be said that the principles of cooperation are the first example of CSR in which-in a bottom-up and non-paternalistic way-the interests of individuals and those of the community are jointly considered.

Table 1. Congruence between the principles of cooperation and economic sustainability of the cooperative enterprise.

\begin{tabular}{|c|c|}
\hline Cooperatives Principles [28] & Economic Effects \\
\hline 1. Voluntary and Open Membership & $\begin{array}{l}\text { - } \quad \text { Freedom of entry and exit; } \\
\text { - } \quad \text { Respostability of the extra profits; } \\
\text { opportunistic (self-control vs. } \\
\text { ophavior). }\end{array}$ \\
\hline 2. Democratic Member Control & $\begin{array}{l}\text { - Symmetric information; } \\
\text { - Sharing of responsibility (democratic } \\
\text { - } \quad \text { Nontrol cons. auto-referentiability of shares ant equal right } \\
\text { of participation (common goods and social } \\
\text { capital not privatizing). }\end{array}$ \\
\hline 3. Member Economic Participation & $\begin{array}{l}\text { - } \quad \text { Auto limitation of the profit distribution; } \\
\text { Endogenous sources of financing; } \\
\text { - } \quad \text { Rentestability of extra profits; } \\
\text { opponsibility (self-control vs. } \\
\text { opportustic behavior). }\end{array}$ \\
\hline 4. Autonomy and Independence & $\begin{array}{l}\text { - Corporate social responsibility; } \\
\text { - } \quad \text { Autonomous economic choices; } \\
\text { Economic criteria in the resource allocation. }\end{array}$ \\
\hline & $\begin{array}{l}\text { - Symmetric information; } \\
\text { - Internalization of the costs in human capital } \\
\text { investments: }\end{array}$ \\
\hline $\begin{array}{l}\text { 5. Education, Training, and } \\
\text { Information }\end{array}$ & $\begin{array}{ll}\bigcirc & \text { Human resource reproduction; } \\
\bigcirc & \text { Competences development; }\end{array}$ \\
\hline & $\begin{array}{l}\text { - Relational goods implementation; } \\
\text { Intergenerational transmission of skills, } \\
\text { values, and resources; }\end{array}$ \\
\hline 6. Cooperation among Cooperatives & $\begin{array}{l}\text { Formation of relationship networks. } \\
\text { - } \quad \text { Rewer transaction costs; } \\
\text { - } \quad \text { Redipply-chain partiners and consumers; } \\
\text { (exponsibility using the market power } \\
\text { (example: Fair Trade). }\end{array}$ \\
\hline 7. Concern for Community & $\begin{array}{l}\text { - } \quad \text { Respect of the rules; } \\
\text { - Internalization of the social costs; } \\
\text { - } \quad \text { Reoling of the individual and social risks; } \\
\text { induced social costs. }\end{array}$ \\
\hline
\end{tabular}

Source: Own presentation. 
The cooperative movement demonstrates that the nature of the enterprise includes all the internal and external resources defined and used by the company itself, within the limits of the exercise of the rights of the different stakeholders. The full exploitation of these resources (for example, the work or the product of the members or other physical or intangible assets in common) faces the economic problem of modifying the reasons of exchange (e.g., deriving by monopoly, low wages, or low product quality), that have determined the misuse or degradation of the capability of the factors.

According to the hypothesis of perfect competition, the cooperative enterprises are theoretically inconsistent because the factors are always given - in quantity and qualityand remunerated in function to their contribution to the production; moreover, they are empirically dangerous because of their attempt to alter the "natural" prices, arising the risk of a permanent market failure, encouraging monopoly rents, opportunistic behavior, and negative externalities. In other words, violating the rules of competition, they risk giving way to the forces pushing toward the "dark side" of the economy.

As known, the main objective of the cooperative enterprise is to integrate and share the use of goods owned by its members (work, machinery, skills, etc.), avoiding the systematic risk of partial use, normally arising if there are conditions of low economic fertility (small dimension of enterprises, fragile areas, or difficult condition of processing). Thanks to the cooperation, super-additive conditions can be generated even when individual resources are fragile or dispersed, achieving economies of scope or scale on which the sustainability of the enterprise is based. In the case study of the paper, these forces operate continuously, supporting the entire agri-food system. Therefore, the first innovation of the modern cooperative enterprise is to have understood that the respect of the mutualistic exchange rules is a factor producing value; so, it must be remunerated as the other production factors. As pointed out by a vast literature [29,30], this factor can be considered an asset of the overall SC, and its "remuneration" is the Patronage Refund.

The economic convenience of cooperation is only one of the basic conditions to realize a cooperative. Indeed, the SC deriving by mutuality must be continuously reproduced, enlarged, and passed on to the future generations of members. Therefore, the SC is the product of an eco-social process made possible by the implementation of the seven necessary conditions of cooperation, which define the corporate pact (definition of rights). Table 1 outlines how the seven principles have a precise content of both private economic rationality and sustainability, incorporating into the business costs the maximum of the induced "social" costs. This allows building a congruence between the micro conditions of cooperation and the macro conditions of sustainability of the system, as shown in Table 2. In particular, if the microsystem of the cooperative enterprises remains open, respecting principles 6 and 7, there is a systematic reproduction of SC. We will see later an important example of such synergistic effects in the case study presented. 
Table 2. Congruence between the rules of the cooperative pact and the conditions necessary for the functioning of socio-ecological systems.

Cooperatives Principles

Commons Principles

1. Voluntary and Open Membership

2. Democratic Member Control

3. Member Economic Participation

4. Autonomy and Independence
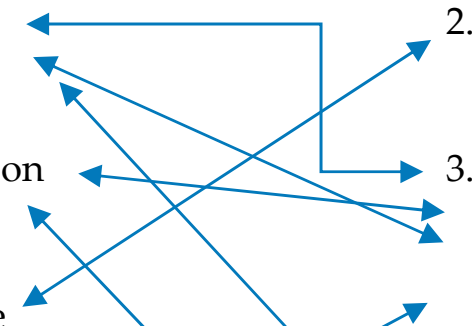

5. Education, Training, and Information
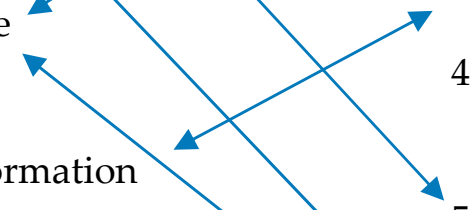

6. Cooperation among Cooperatives

7. Concern for Community

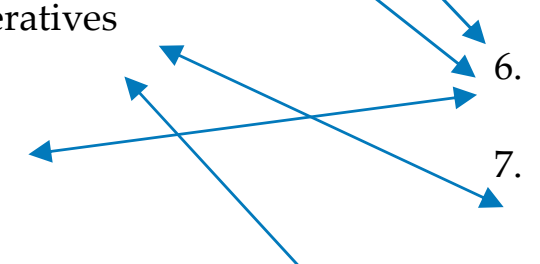

1. Clearly defined boundaries (effective exclusion of external unentitled parties);

2. Rules regarding the appropriation and provision of common resources are adapted to local conditions;

3. Collective-choice arrangements allow most resource appropriators to participate in the decision-making process;

4. Effective monitoring by monitors who are part of or accountable to the appropriators;

5. There is a scale of graduated sanctions for resource appropriators who violate community rules;

6. Mechanisms of conflict resolution are cheap and of easy access;

7. The self-determination of the community is recognized by higherlevel authorities;

In the case of larger common-pool resources:

8. Organization in the form of multiple layers of nested enterprises, with small local common pooled resources at the base level.

\subsection{The Forces of the "Dark Side" and Social Capital Measure}

As has been said, the measure of the productivity of the SC is its contribution to increasing the sustainability of the ecological-social system that uses it. Claiming that an ecological-social system "uses" the SC means that the SC - as well as grain or any capital factor-is an input factor (grain-seed), a process fund (grain-sown) and, finally, an output of the process (grain-harvest) [25]. However, on the empirical level, the cause-effect relationship between availability and use may change, depending on the unit of analysis. For example, as for the capital factor, it is not possible to measure the SC supplied by a single company or by the whole system in an unambiguous way.

To measure SC, the focus needs to shift from the visible effects (e.g., the existence of social networks) to the effectiveness in the application of the rules defining the commons produced (Table 2), which affect sustainability. Compliance with the previously defined sustainability criteria guarantees the good use and fertility of resources, and this aspect can be measured through appropriate indicators in relation to the type of analysis unit: mesoeconomic (e.g., environmental degradation or long-term unemployment rate duration, etc.) or microeconomic (working conditions, waste production, product quality, degree of SCR, etc.). Therefore, the survey shifts from traditional and unclear SC indicators to new sustainability indicators, for instance, according to Table 2. 
If the SC and sustainability are factors of the economic process, we may suppose that the misreproduction of the fertility conditions of SC and decay move in the same direction. The decay of the fertility is in both cases the result of the destruction engendered by the disappearance/lack of respect of one or more of the necessary conditions, at the micro or macro level, supporting the reproduction of the non-private goods. Therefore, the indicators for measuring the degradation of sustainability-e.g., using in a correct way indicators for the Sustainable Development Goals (17 SDGs and 169 Target) of the UN Agenda 2030 [31,32]— these may be applied also to measure the SC, limiting the risk of ambiguity discussed in the debate on the dark side. For example, in the case of the mafia system, many indicators currently used to measure SC are observed with a positive value, such as cohesion of relational networks, trust, cooperation, and solidarity. However, the indicators are induced by conspiracy of silence and limited to the members of the group. Consequently, the mafia system is an establishment of monopoly power acting on the control of factors of demand and supply, such as the control of the labor market or of goods and services. The mafia monopoly has a power guaranteed by its closed system and use of violence, preserving a given hierarchy of power. If apparently positive indicators of SC are observed (dark side), the full conditions of SC sustainability are missing, such as the definition of the rights of access and of the participation in the management. As seen in Tables 1 and 2, the rules just recalled are important to guarantee open communities and to avoid the risk of preserving monopoly power or position rents. Adherence to all the conditions listed in the tables is the necessary condition to observe SC avoiding the risk of "dark side".

An open system implies that it is not possible to assume ex ante a condition of automatic and stable equilibrium, and it is necessary to balance the internal contrasting needs and interests that constitute the nature of all social dilemmas of protection of individual versus social interests (Ostrom 2007) [18-21]. From the external side, it is necessary to react to the exogenous shocks (effects of the economic crisis or of the extreme events), maintaining the whole system and the balance of private and collective internal interests, using the existing SC.

If the unit of analysis is the cooperation, the balance between the self-production of SC and the economic sustainability of the enterprise is determined by the respect of all the circumstances reported in Table 2. The same conditions apply to the full cooperative production system and movement. In the case of a specific production, all the chain is interested in the same rules as in the case study presented in the following pages. This respect roots the production of SC and of the sustainability of the system. Positive benefits may also affect the area where the production is located, as in the case study presented. The recalled conditions are the basis of the fertility of the resources of the system, enabling its reproducibility, respecting the criteria of our definition of sustainability.

\section{Material and Methods: The Case Study of Parmigiano Reggiano (PR) Supply Chain}

The paper analyzes as an in-depth case study the PR cheese supply chain, which is a production that has a great relevance in the Italian agri-food sector and where the cooperation has a very relevant role. The investigation uses information collected by focus groups and interviews with producers and representatives of private and cooperative enterprises which allowed testing the main theoretical hypothesis on the Commons and on the SC theories. The general description of the chain is made using statistical data of the district, which are collected and elaborated by the sites of the Consortia (PR Consortium and CPQR Consortium). The test of the theoretical hypothesis about SC and the role of cooperation is made through the analysis and elaboration of data combining the three main archives on budgets, technology, and physical production. 


\subsection{The PR Supply Chain as an Eco-Social System}

The history of the Italian cooperation movement is an important part of the history of the entire agri-food sector, especially in the most developed regions of North Italy. The case study of the paper is in Emilia-Romagna, which is a northern region offering one of the best examples of the economic strength of the cooperative movement in Italy. Given the strong presence of the cooperative movement since its origin, in the classic work of Putman [33], this area was the main laboratory for the empirical analysis, definitions, and proposals of the first indicators to measure SC. Currently, cooperative enterprises handle a great part of the agri-food activities, which represent the second productive sector in the Italian and regional economy. The cooperative movement has a crucial importance in the traditional products of the "made in Italy" trademark, which is well known at the international level. They are protected by European Union (EU) specific marks (DOP), which guarantee the link of the product with a specific and limited territorial area and its tradition. The mark defines specific rules of production, limiting the boundaries of the economic evolution of the production system in terms of its possible geographical expansion, raw materials processed, and way of producing. Innovation needs to take into consideration all the limits imposed by the DOP. The object of the case study refers to one of the most important products among these ones, the PR.

The description of the production process of PR is apparently very simple and organized in the main stages of milk production, processing, seasoning, and marketing, and it is not dissimilar to what happens in all dairy business. However, the compliance with the quality rules required by the DOP constitutes the identity of PR. The aim of the case study discussion is to show that the SC deriving by the complex action of cooperation inside the PR chain makes the production sustainable and maintains the balance among numerous economic agents, mainly SMEs, acting also as a fundamental element of economic support for the entire ecological-social system of a large territory. In this regard, the paper outlines the role of cooperation in all the production phases and especially in the control, reproduction, and reinforcement of the social pacts linked to the respect of the mark and defined by the social production rules. The acceptance/sharing of these rules, their control, and sanctions, is one of the main aspects of SC in the supply chain, representing an economic asset and a common good available to all agents and consumers.

Moving from Ostrom's results summarized in Figure 1, it is possible to see how the action of cooperation inside a PR chain allows reproducing and enlarging SC, straightening all the production chain and also including the private no-cooperative economic actors. Figure 2 adapts the MO scheme of Figure 1 to the PR supply chain with the aim of showing how the interaction of different elements of MO builds or straightens SC as a system of non-private goods benefiting all the chain agents. An example of such goods, among many others, is the agreement among PR producers and institutions such as the Ministry of Agriculture, Region, and Antitrust for the definition of individual quota of production for milk, in coherence with the respect of the market rules and the open system of cooperation for the full chain [16]. Given that the chain is spread all over the district of production, it plays a crucial role in maintaining the population of the territory, especially in the fragile areas of the hills and mountains, in reinforcing SMEs, and in balancing the development of the area. In other words, it regenerates the resources used in the process of production and their fertility, being a good example of a sustainable socio-economic system according to our definition. 


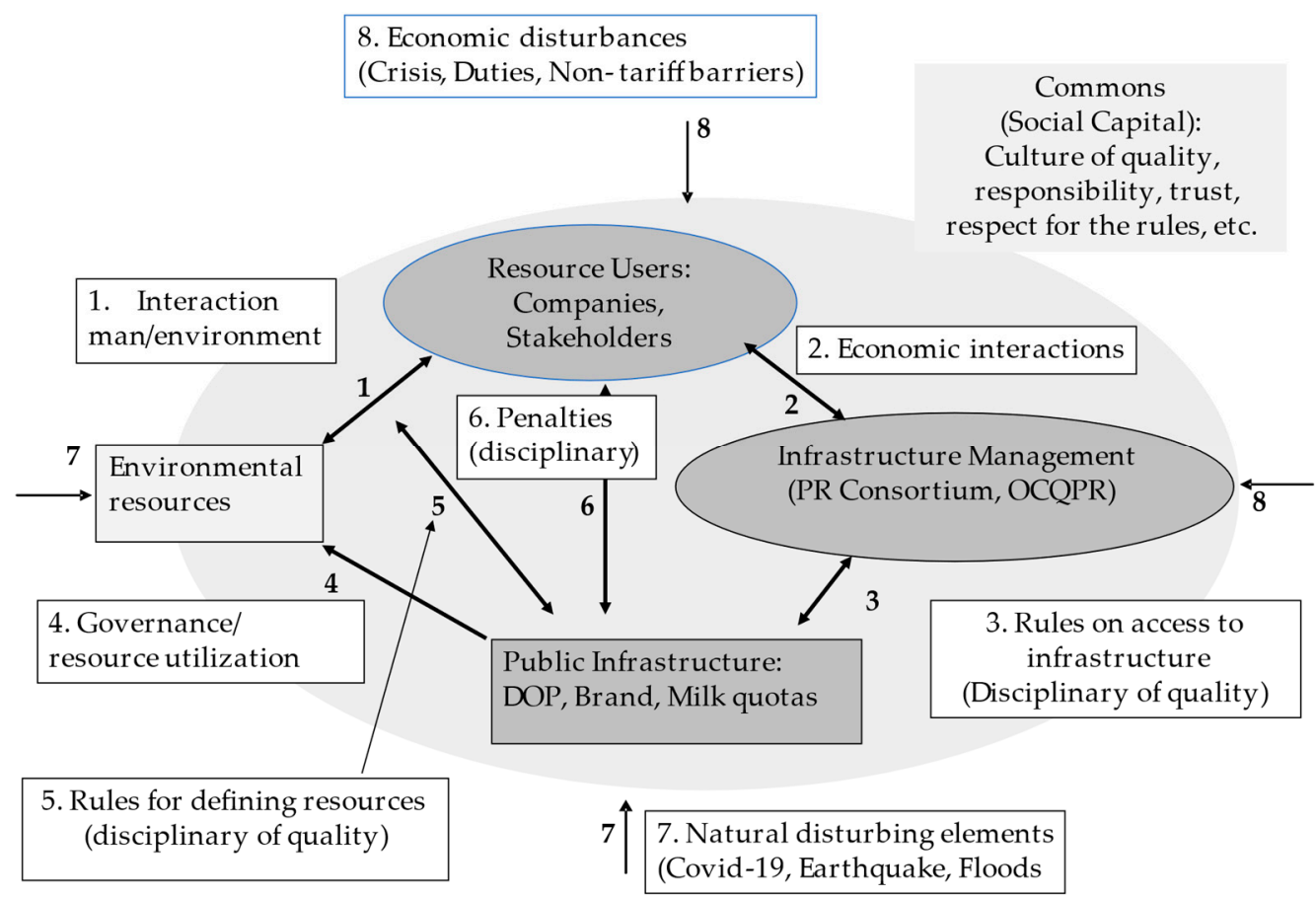

Figure 2. PR as social-ecological system and social capital in the supply chain. Source: Own presentation.

\subsection{The Role of Cooperation in the PR Supply Chain}

According to the definition of SC given, where rights and duties play a strategic role, the main aim of this section is to show how the cooperative institutions operating in the PR chain have developed paths to defend and increase the SC, such as mutuality, which also improves the efficiency of the markets for factors and products. This action allows implementing the behaviors of the agents coherent with the sustainability as an assumption of responsibility toward shareholders, firms, and the communities in which they operate. This corresponds to the definition of sustainability used in the paper.

The cooperation played a crucial role in promoting the common rules (disciplinary) for producing PR and the quality mark, which required a long social process of acceptance by all the producers of milk, dairy processors, seasoning, and distributors. For instance, the disciplinary board bans the use of chemical additives for processing milk, and this constraint affects all the production phases. The very high quality of milk, which is necessary for seasoning the product for a minimum mandatory of 12 months, requires precise constrains in the feeding and welfare of animals. The disciplinary board has other important effects in the organization of the production and in innovation. For example, the rules for processing milk limit the vertical integration of the plants in the first step of the process, impeding the industrial organization in many daily cycles, as done by other competitors such as Grana Padano cheese $[16,17]$. As we will see later, this makes it very difficult to achieve economies of scale by increasing the plant size.

Given the limits defined by the disciplinary and shared by the multiplicity of small firms in the chain, the history of the cooperation into the supply chain outlines a continuous balancing of the two following constraints: (a) coordination between the different phases of production to assure regular flows of the product in quantity and with the respect of quality rules; (b) decision on the distribution of the costs for funding the production, whose final value depends on the length of seasoning, with a minimum of 12 months and up to 5 years. The possible decisions influence the choice "make-or-buy" of the enterprises and, therefore, the degree of integration of the phases and the of division of labor inside the chain. These problems are enlarged by the great territorial dispersion of small size milk-producing farms. 
The structural conditions described occur also in many areas of the Italian agrifood sector, especially in disadvantaged areas [34]. Thus, given the risk arising from the fluctuations of the prices in the agri-food activity, the market structure is often organized around hierarchical oligopsonistic relationships, where the market power is exercised by those who control the final demand. In a market of independent firms, the higher costs deriving from the risk of price fluctuations are outsourced on those with not have market power in the supply chain (usually processors, seasoners, distributors, and financial sector).

In this context, a cooperative pact is sustainable if it manages to overcome many constraints to modify the map of the distribution of the costs and benefits along the chain, deriving by the current activity and by the expected results. Therefore, the structure of transactive costs among agents must change, arising relevant questions (social dilemma) for a private agent, and especially the main question of whether to accept or not the cooperation pact. For example, what is the convenience of accepting a cooperative agreement that constitutes an objective limitation on the private business autonomy, instead of giving milk to a private dairy offering better economic conditions in the short term? Why pool resources with a limited personal control of them? The size of the transactive costs is a function of the size of the social dilemma, which requires overcoming the short-term interests for accepting an uncertain long-term perspective [35].

A single farm has difficulties estimating the current costs of processing milk and the full process of production. On the contrary, this information is usually known by the dairy companies, using the same technology and purchasing the milk in the same way, making a situation of asymmetric information among agents and oligopsonistic power. In these circumstances, the price set in the market is, in fact, the result of implicit collusion among the processing companies, with the effect of limiting the search for better market conditions by the milk producers. In this situation, the development among farmers of a cooperative pact to promote a dairy phase makes transparent the industrial costs of processing, seasoning, and so on, benefiting the members of the cooperative and also all the agents of the chain, for instance through the transparency of the budget or the other activities of the cooperative. As a consequence, the spread of cooperation reduces the asymmetric information and increases competition, producing an open system where the shared information is an important asset of the SC of the entire supply chain. In the following pages, and especially in the Section 4.3, we will present data showing the effect of cooperation in the price formation and outlining that the prices paid by the cooperation are in fact the benchmark for the entire chain.

In the PR chain, there has been a significant presence of cooperation since the 1950s, especially in dairy and along the full chain, showing the economic effectiveness of the cooperative firm, which is evident in its long persistence and in its leader role in the chain. The economic strength of the cooperative is the direct result of the application of the principles listed above in Table 1, where economy is a relevant aspect. If the seven principles are fully respected, the cooperative pact is sustainable, and it will produce enterprises that are able to successfully face the market thanks to the many benefits produced by cooperation: increasing the productivity of the resources, generating new skill, maintaining, and enlarging the economic asset of the enterprises to the next generations, promoting innovation, achieving economies of scale and scope also for SMEs, and so on.

The theoretical objection that has always been raised to cooperatives is that the same objectives can be achieved more quickly and efficiently by private enterprise. However, while the attention of the private firm is limited to private interest, the cooperative has a larger vision, producing larger benefits. For example, the cooperation establishes longterm commitments with the owners of the resources used, with a reproduction of SC, in coherence with sustainability according to the definition given before: the constant use and valorization of the asset (labor, capital, skills), the access to common tools for producing, and the spill-over of knowledge, all of which derive from the respect of the rights, as in the case of cooperative dairy of PR, and are common economic resources synergically reproduced. 
Therefore, it is not surprising that the cooperative enterprise is the predominant form of enterprise in the supply chain structures in the Parmigiano Reggiano sector. The phase in which it is most present is the transformation of milk, which is essential to the quality of the product. However, there are important examples of cooperative enterprise also in the breeding phase, as well as very sophisticated forms of cooperation between cooperatives (cooperatives of second degree and consortia) in the downstream phases, where they have a preponderant economic weight, especially in seasoning and distribution. The current PR structure is the result of a long evolutionary process, which took place in similar ways in other sectors and countries [34,36-38].

\section{Results of Empirical Research}

\subsection{The SC of Cooperation and the Structure of the Supply Chain}

Table 3 shows the principal information about the variations in the structure, localization, and production of the enterprises in the PR district in the 2010-2017 period.

Table 3. PR district: farms, dairies and production (2010-2017).

\begin{tabular}{cccccccccc}
\hline \multirow{2}{*}{ Zone } & $\begin{array}{c}\text { Farms } \\
\mathbf{2 0 1 0}\end{array}$ & $\begin{array}{c}\text { Farms } \\
\mathbf{2 0 1 7}\end{array}$ & $\begin{array}{c}\text { Var. Farms } \\
\mathbf{2 0 1 0 - 2 0 1 7}\end{array}$ & $\begin{array}{c}\text { Dairies } \\
\mathbf{2 0 1 0}\end{array}$ & $\begin{array}{c}\text { Dairies } \\
\mathbf{2 0 1 7}\end{array}$ & $\begin{array}{c}\text { Var. Dairies } \\
\mathbf{2 0 1 0 - 2 0 1 7}\end{array}$ & $\begin{array}{c}\text { Tons Milk } \\
\mathbf{2 0 1 0}\end{array}$ & $\begin{array}{c}\text { Tons Milk } \\
\mathbf{2 0 1 7}\end{array}$ & $\begin{array}{c}\text { Par. } \\
\mathbf{2 0 1 0 - 2 0 1 7}\end{array}$ \\
\hline Plain & 2316 & 1992 & $-14.0 \%$ & 280 & 242 & $-13.6 \%$ & $1,278,111$ & $1,481,703$ & $15.9 \%$ \\
\hline Mountain & 1207 & 1051 & $-12.9 \%$ & 114 & 93 & $-18.4 \%$ & 356,127 & 425,553 & $19.5 \%$ \\
\hline Tot. District & 3523 & 3043 & $-13.6 \%$ & 394 & 335 & $-15.0 \%$ & $1,634,238$ & $1,907,256$ & $16.7 \%$ \\
\hline
\end{tabular}

Production increased by $16.7 \%$, while the number of farms and dairies decreased, respectively, by $-13.6 \%$ and $-15.0 \%$. Therefore, there has been a general process of increasing the production capacity of farms and an increase in the size of companies through acquisitions, mergers, and restructuring.

Apart from the cooperation, the PR chain has the following two main typologies of noncooperative enterprise: first, the craft dairy enterprises, usually buying milk on the market, specialize in processing the milk and then sell the product after at least 12 months. Secondly, private firms integrate all the production phases, including breeding, processing milk, seasoning, and marketing. To empirically outline the role and the weight of cooperation in the chain, we start from Figure 3A, which shows the relevance of the three different types of firms just described. During the twenty-year period observed in Figure 3A, the structure of the sector has changed in a not-negligible way: the cooperative firm maintains and reinforces its prevalent role in the chain in processing milk even if there is an increasing growth of the other two types of firms.

Figure 3B outlines the production trend of the sample analyzed-divided into cooperatives and private-in 2010 and 2017. Most of the enterprises increase their production, which is on average proportionally to their previous size. This causes a general shift of enterprises toward larger average dimensions, leaving unchanged, in general, the distribution of enterprises. 


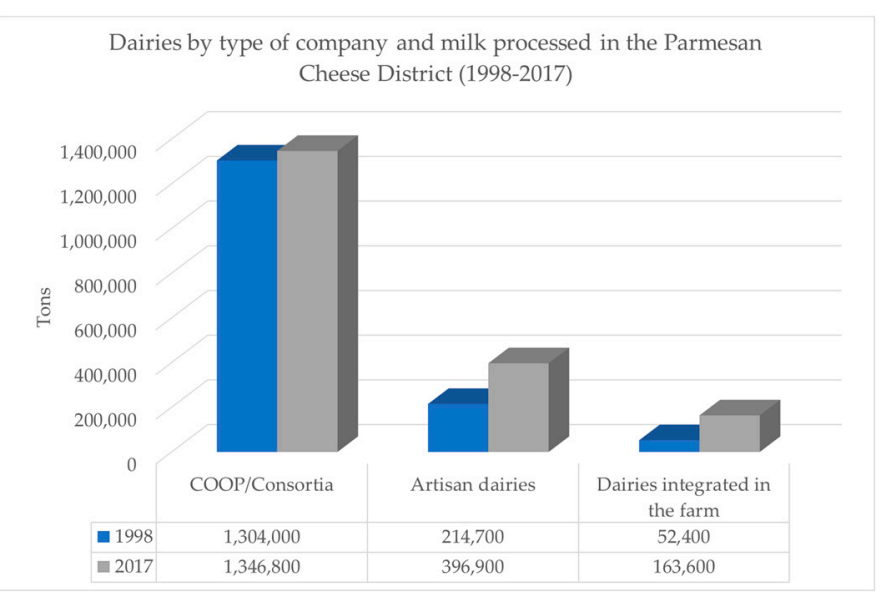

(A)

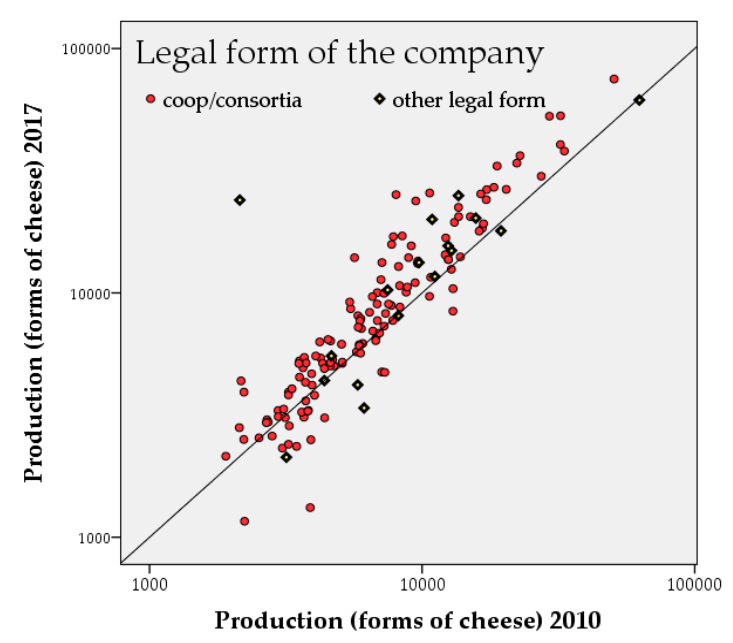

(B)

Figure 3. Growth of production capacity (A) and structural changes of milk processing companies in the PR supply chain (B). Source: Own presentation.

The general growth of production allowed a diversification of typology of firms and increased the division of labor inside the chain, with the search for a greater specialization, for instance differentiating the final product according to the emerging need by consumers and distribution (portioning, length of seasoning, organic, animal welfare label, selection of local traditional animals, etc.). In the general growth shortly described, all the typologies of enterprises, cooperative and not cooperative, co-exist in a self-regulated system, with clear rules and institutions controlling their respect, making the entire system open and competitive. In the described framework, the socio-economic system stimulated by cooperation played a crucial role. For example, the institutional action of the cooperative movement has been very relevant in promoting the coordination among the different agents of the chain for maintaining in a dynamic equilibrium milk supply, milk demand for processing, structure for seasoning, funders, and distribution. Moreover, the cooperation plays a fundamental role in the control of the external shocks thanks to an internal insurance mechanism for its members [39]. Above all, the case study shows that adherence to the cooperative principles of Table 1 allows increasing the transparency in the distribution of the value among all agents of the supply chain as well as increasing competition. In this regard, it is understandable that the US Department of Agriculture in 1922 with the Capper-Volstead Act-considered the Magna Carta of cooperation in the USA—approved the role played by competition in the cooperative system, thanks to the principle of the open door, the democratic control of "one head one vote", and the self-restraint of profit. This act has allowed US cooperation to develop extensive supply chain coordination over time without incurring the rigors of antitrust [40].

\subsection{Constraints on the Dimensional Growth of Plants and the Development of Enterprises}

As seen before, the rules of $\mathrm{PR}$ reduce the possibility of achieving significant economies of scale through the integration of the process inside the same plant. Given this constraint, the increase in production has been possible thanks to the implementation of economies of scale/scope in different phases of the process of production. The search for economies of integration (scale and scope) needs a steadily increasing of milk flow over time. In a competitive market, an enterprise can decide the level of production capacity but not the size and stability in supply of the factors or of the final demand. On the contrary, in a noncompetitive market, the company can achieve a stability of operating conditions through the exercise of the power of monopsony/monopoly. In our case, stability in the operating conditions of all the actors is achieved through the institutional coordination: the modern history of cooperation in the agri-food sector in general, and in the PR chain too, has shaped 
and strengthened all the institutions of coordination of the supply chain-cooperatives and consortiums, formal and informal—with the aim of maximizing the economies in all the production phases [35] (p. 15).

The data represented in Figure 4, related to the sample of companies studied, provide a possible stylization of the effects of the two main constraints-coordination of phases and territorial dispersion-on production costs and, therefore, in the development path followed by companies.
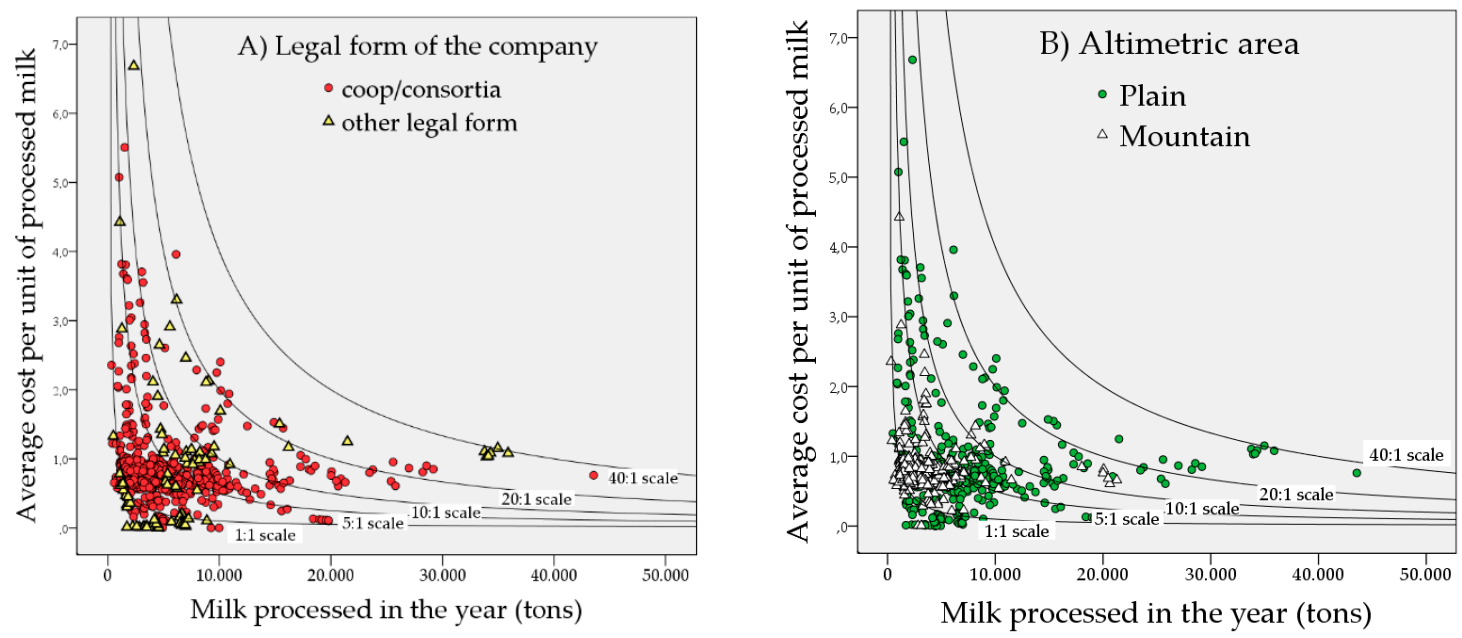

Figure 4. Structure and trend of average processing costs: (A) by type of company; (B) by altimetric area (2009-2017). Source: Own presentation [17].

In the figure, the companies are divided into two sets: by legal form (panel A) and by altimetric area (panel B). The distinction is important, because the operating conditions in the mountain area are more difficult (reduced average size of agricultural enterprises, territorial dispersion, logistical difficulties, depopulation). The points represent the average costs of a single enterprise relating to one-year financial statements. The microdata of physical production refer to a minimum of three observations that allow seeing the evolution of cost in relation to the degree of capacity utilization.

The theoretical trend of costs is largely predictable according to a $k / x$ model, where $k$ indicates the fixed costs given the available production capacity and $x$ is the variable quantity of product processed. Given the minimum level of fixed costs, observable from the budget data, we imagine that this represents a proxy of the costs of the elementary process: the minimum sectorial level of $k$. It is possible to trace the trend of the expected average costs when the production level $x$ on the plant changes (1:1 scale curve). By repeating the exercise, at different scales with $k$ up to 40 times bigger, the theoretical curves of the average costs can be traced as a function of the quantity produced and in the hypothesis of a complete absence of economies of scale (constant returns of scale).

Given these curves, from a theoretical point of view, if the companies really would enjoy significant economies of scale, we expect a fall below the reference lines of the average costs with the growing of the available production capacity and of the volumes of the processed product. On the contrary, the hypothesis is not confirmed by the trend of the data, and it cannot be excluded that the mere attempt to increase the size of the transformation may also lead to diseconomies of scale. However, the comparison between the two graphs provides further useful information:

- With the equal volumes transformed, the cooperative dairies have lower average costs. Exceptions are some private old microstructures-particularly in mountain areawhere the absence of new investments makes the costs of amortization negligible.

- The processing facilities in mountain areas are all carried out in smaller-scale plants due to the difficulty of collecting a flow of milk without increasing transport costs. The 
role of cooperative enterprises is predominant, although many plants-the smallestare private artisan dairies.

- A not negligible number of dairies have a very low degree of capacity utilization (high average costs). This is an indicator of structural difficulties in the supply and coordination of milk flows influenced by the change in the structure of breeders: i.e., the abandonment of breeders, or the transfer of their activity or the production quotas to another area. Another difficulty may be the disagreement on the economic decision of the dairy (conditions of sale, funding, etc.). In general, given that the milk market is competitive and that there is the principle of the open door, modifications in the agreements among companies may engender structural changes, inbound and outbound, with significant repercussions on the degree of utilization of the production capacity of dairies and, therefore, on the level of the average costs.

All the individual cooperatives, and still the cooperative movement, through their representatives and in the daily relations with the firms, have faced these phenomena when implementing processes of coordination of the supply chain. The path followedalso marked by serious failures-started half century ago from a systematic attempt to rationalize the dairy network through agreements, mergers, and incorporations. However, as seen in the last graph, there are limits in achieving economies of scale. Despite these difficulties, the cooperation has always sought to increase the integration of the different phases, seeking not only economies of scale through the promotion of a continuous process of innovation compatibly with the disciplinary but also searching for economies of scope, implementing the coordination of the different agents of the supply chain. Figure 4 outlines the positive results reached by the cooperation thanks to this action of coordination.

\subsection{The SC of Cooperation: Economic Performance of the Cooperative Enterprises versus Other Forms}

The process of implementation of SC in PR, as it appears today, started at the end of the 1970s with the decision by the cooperative central management and by the local public institutions to seek economies of scale by integrating the existing dairies, with the aim of gaining competitivity and limiting the negative effects of the PR prices fluctuations. Both the region and the provinces supported the not-easy process, which is finalized to overpass the limits arising by the large presence of SMEs in the chain, especially in the disadvantaged areas, where old and small farmers, often without successors, were most of the social composition of the cooperative processing milk.

The aim to increase the physical size of the plants did not face difficulties, while the acceptance of the aim by the social base of the cooperatives did not represent an easy task to reach. Indeed, the effort to broaden the social base of the new cooperatives through mergers changed the identity of the previous team, which was strongly linked to the specific history of the group of founding members. The action of the coordinating institutions encouraged all the principles of the cooperation, especially emphasizing the "open door" and "democracy" through a bottom-up participatory decision-making process.

However, the economic benefits of the increased scale of production were limited and pushed to the search of other economies: gradually incorporating services of production; seeking neighborhood economies in the seasoning phase; implementing a process of institutional and economic innovation connecting the cooperative to new corporate brands (consortia of second and third degree). Each step involved innovation in agreements among cooperatives with a continuous and not easy balance of the different interests, which was a process supported by SC deriving by the previous experience of cooperation and producing new collective material and immaterial goods, enlarging the SC. For instance, the difficult decision to distribute the patronage refunds according to the quality of milk enlarged both productivity and new skill; in turn, the new attention of the agents toward quality required at the beginning a capacity of negotiation among members to accept the innovation, the related decision of investment, the system of control, and the new form of payment. All the aspects engendered material and immaterial benefits that enlarged cooperation SC. 
Moreover, the successful innovation was fast imitated along the chain, expanding the common goods that benefit all the actors of the system.

The graph in Figure 5 shows the values of indicators elaborated by the financial statements of all the PR companies, comparing the performance of cooperatives versus other forms of enterprises.

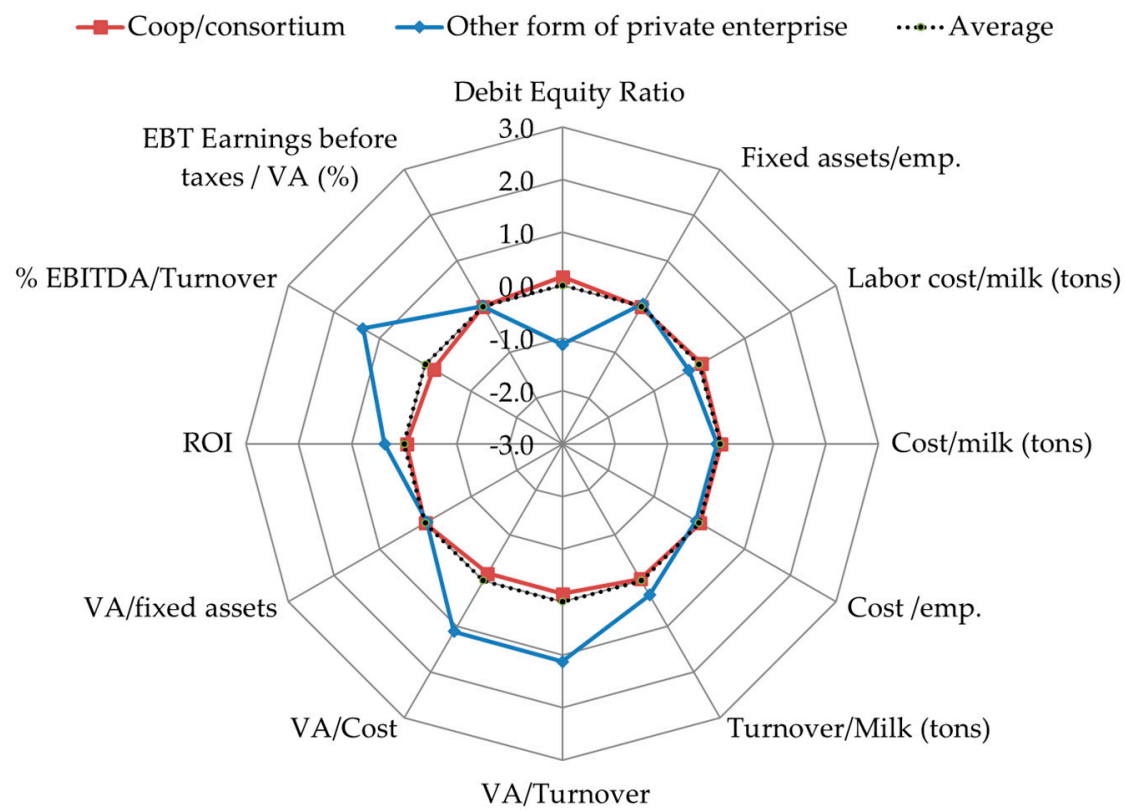

Figure 5. Economic indicators for the form of enterprise (standardized median values). Source: Own presentation.

In order to be compared, the indicators were standardized (Z-variables). For all the indicators of economic structure and performance, the results outline the absence on average of statistically significant differences between cooperatives and other companies. According to the standard economy, this may be the result of the market competition. However, the competition is not the state of nature, and the equilibrium is not a necessary mechanical consequence of the competition. In this regard, cooperation plays a crucial role to realize competition and avoid the monopsony power of processing or distribution, pushing in the direction shown by the graph. The role of cooperation in this regard is outlined by the indicators of the profitability, where there are differences between business models: the private enterprises appear more profitable (e.g., \%EBITDA/Turnover), even if the indicators of the technical / structural aspects (Fixed Costs) are almost homogeneous among all the typologies of enterprises. It must be underlined that the value-added is calculated in a different way: in the cooperatives, the remuneration of milk incorporates not only the cost of production of milk but also the Patronage Refund, as a premium of mutuality, in term of self-financing, risk pooling, enhancement of the resources of the members, and savings on transactive costs. Moreover, for the cooperative, the indebtedness (Debit Equity Ratio) is higher, because it includes the debts of the members without calculating their assets. Consequently, the different level of cooperative indebtedness is done as a constraint for the cooperative budget structure imposed by the Fiscal Authority and does not refer to a weakness of the cooperative enterprise. At the opposite, the higher profits of the companies derive by the minimization of business risk financed by a lower remuneration for milk (and labor) on the free market.

In other words, the different performance of the two types of enterprise suggests the active role of cooperation in the distribution of the income among all agents (farmers, dairies, labor, seasoning, marketing, etc.) and in the regulation of the prices of the factors, stabilizing the entire chain. 
Figure 6 shows the Value Added and Turnover ratio trend (2009-2018) by the legal form and size of the company, which adds some interesting specifications, showing the ten-year trend of the ratio between VA/Turnover in the different types of firms and by size. For the years considered, the graph shows the differences in the median values (black line inside the bars) and in the variability of the index (width of the bars). Three relevant facts are visible:

- Over the entire period, for cooperatives and independently by their dimension, the index is substantially stable in its level and variability (size bars).

- Large private dairies behave no differently from cooperatives.

- In private dairies of smaller size, there is a progressive reduction of the indicator and a convergence with the values of other companies (especially in peripheral mountain areas).

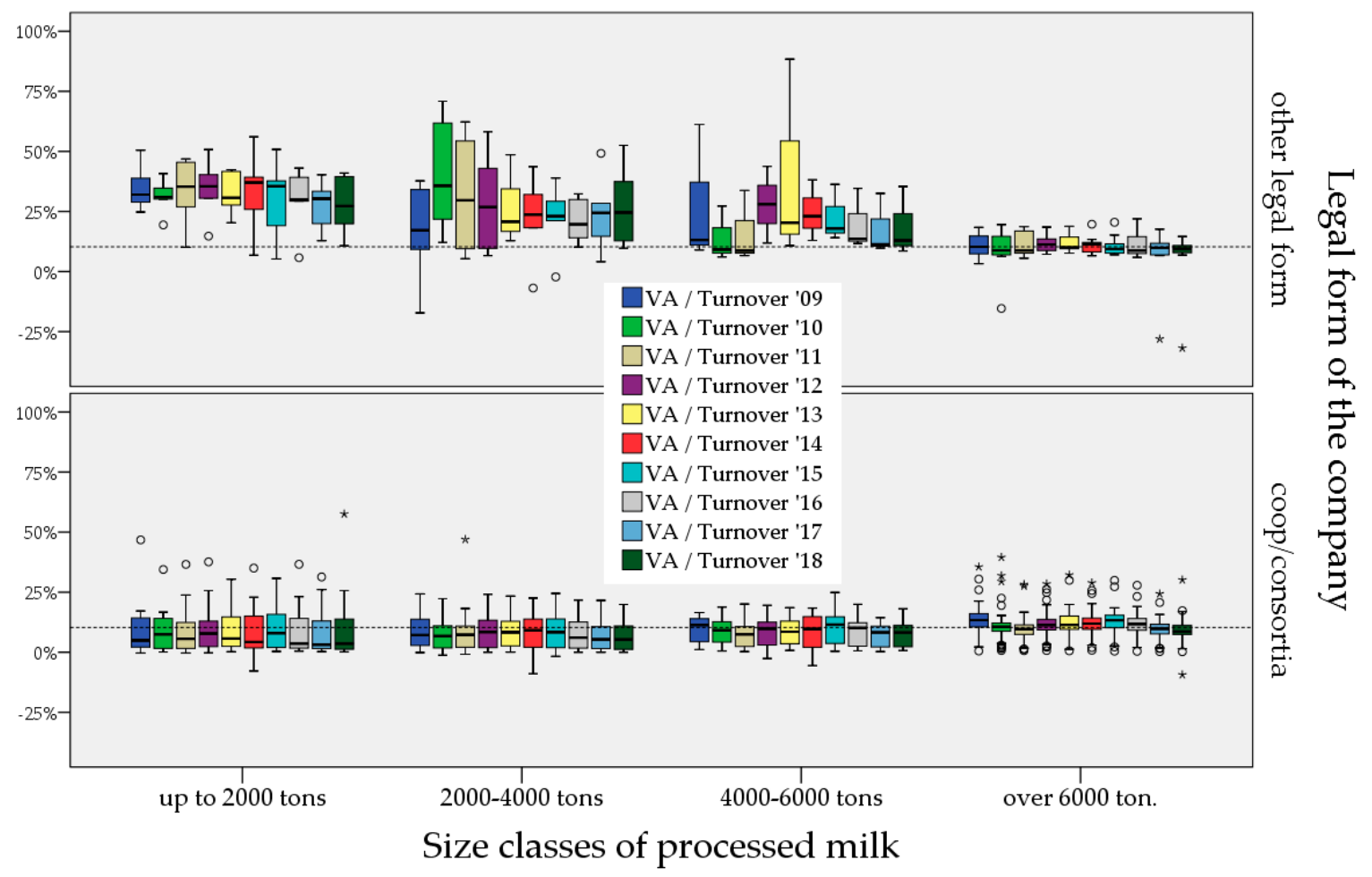

Figure 6. Value Added and Turnover ratio trend (2009-2018) by legal form and size of the company. Source: Own presentation.

In the period considered, the PR sector has always grown and has never suffered downward shocks in prices. Then-for the firms using the same technology and with the same labor costs-the value of the index may be considered a proxy of profitability for the ownership rights of the company versus the prices paid to the milk producers. However, we have seen that the role and economic weight of cooperation affects the income distribution of factors and, in turn, the general operating conditions of the entire sector. These conditions are also reflected in the prices/costs structure of the largest private companies that are in continuous competitive comparison with the cooperative sector, both on the raw material market and on the intermediate and final markets. Therefore, dynamically-even if there are differences between cooperatives and other forms of enterprises, especially in the smaller size classes-the whole price/income system tends to converge, in terms of levels and degree of variability (proportional to the width of the bars), on the values of cooperative companies. 


\section{Conclusions}

The main purpose of this work was to show the nature of the SC (set of non-private assets) and its role in determining the greater sustainability of the system in which it is created and maintained. For this reason, the measure of the productivity of SC is its contribution to increasing the sustainability of the ecological-social system that uses it. $\mathrm{SC}$ is not a resource existing in nature but is the result of collective choices characterized by precise assumptions of responsibility and commitments. Having therefore defined the general theoretical framework, an attempt was made to observe how and why agents undertake coherent collective choices, which establish pacts and form institutions capable of regulating coherent behavior in balancing short-term individual interests and long-term collective interests.

The cooperative enterprise and the rules universally adopted by the cooperative movement constituted the second focus of the work. In particular, the article attempts to show the strong interaction between SC and cooperation in the specific case study provided by the PR chain. It was discussed how the synergies between the action of individual companies and the system are strongly linked to social action that has found solutions to the many emerging problems, balancing different interests, and in compliance with the principles of cooperation. Valentinov's consideration [7], that a high SC available in the social environment of a cooperative produces a greater SC, is verified by the results of the paper, also confirming Elinor Ostrom's aphorism: "Social capital is not consumed with use but rather with disuse" [21] (p. 179). The PR case study is proof of the possibility of following a path of successful development over time if there are positive synergies between CSR, supply chain relationships, local institutions, and regional policies.

In the case study, there is never evidence of significant effects of the so-called "dark side" of the SC, which is attributable to the cooperative action. On the contrary, the cooperative system is shown to be open to competition and a positive benchmark also for other agents not linked to cooperation. In fact, the other operators cannot easily disregard the rules of product quality and the safeguarding of the factors used: manpower, raw materials, the environment. The paper illustrates data and examples of operation of the supply chain in which SC is continuously reproduced. The relationships between agents and the role played by cooperation generate trust, inclusive institutions, non-opportunistic behaviors, fair distribution of income between agents, social and technical innovation. According to the thesis supported in this work, those goods are precisely the testimony of a sustainable eco-social processes, which is made possible by the respect of the set of conditions that regulate the formation and reproduction of all collective goods.

Author Contributions: Conceptualization, E.G. and P.B.; methodology, E.G.; validation, E.G. and P.B.; formal analysis, E.G.; writing—original draft preparation, E.G.; writing—review and editing, P.B. and M.R.; funding acquisition, E.G, P.B. and M.R. All authors have read and agreed to the published version of the manuscript.

Funding: This research was funded by PRISMA project (Parmigiano Reggiano e Innovazione negli Strumenti Manageriali: cruscotto di indicatori di benchmarking e performance delle aziende, nuovi strumenti finanziari e assicurativi, nuove soluzioni logistiche e commerciali), Regione EmiliaRomagna: PRISMA project-Programma di Sviluppo Rurale 2014-2020_REGIONE EMILIA-ROMA GNA FOCUS AREA 3A Operazione 16.2.01, progetto di filiera F7; partner Lattemilia spa, CRPA spa, UNIMORE, BIT spa.

Institutional Review Board Statement: Not applicable.

Informed Consent Statement: Not applicable.

Data Availability Statement: The data used come from different sources: $a$. the AIDA archive, that collects the financial statements of the companies in the ATECO sector C-10.51.00 and C-10.51.20 for all the provinces of PR district (Parma, Reggio Emilia, Modena, Mantua and Bologna) (203 observations) [41]; $b$. date from Agency for the Quality Control of Regulated Productions CPQR (392 observations) [42]; c. Times series data from the PR Consortium on producers and productions of milk and cheese (153 observations) [43]. Data will be available on PRISMA website (under construction). 
Conflicts of Interest: The authors declare no conflict of interest.

\section{References}

1. Ehrenfeld, J.R. Sustainability Needs to Be Attained, not Managed. Sustain. Sci. Pract. Policy 2008, 4, 1-3. [CrossRef]

2. Valera, L. Sostenibilità: Un concetto da chiarire. Econ. Dirit. Agroaliment. 2012, XVII, 39-53.

3. Diamod, J. Collapse: How Societies Choose to Fail or Succeed; Penguin Book: London, UK, 2005.

4. Acemoglu, D.; Robinson, J.A. Why Nations Fail: The Origins of Power, Prosperity, and Poverty; Profile Books: London, UK, 2012; ISBN 978-1-84668-429-6.

5. Jabareen, Y. A New Conceptual Framework for Sustainable Development. Environ. Dev. Sustain. 2008, 10, 179-192. [CrossRef]

6. Giovannetti, E. Sostenibilità ed efficienza. In Glossario Delle Diseguaglianze Sociali; Fondazione Gorrieri: Modena, Italy, 2020. Available online: https:/ /iris.unimore.it/retrieve/handle/11380/1255169/366837/Sostenibilit\%c3\%a0\%20vs.\%20Efficienza\% 20finale.pdf (accessed on 2 November 2021).

7. Valentinov, V.L. Toward a social capital theory of cooperative organisation. J. Coop. Stud. 2004, 37, 5-20.

8. Pillai, K.G.; Hodgkinson, G.P.; Kalyanaram, G.; Nair, R.S. The Negative Effects of Social Capital in Organizations: A Review and Extension. Int. J. Manag. Rev. 2017, 19, 97-124. [CrossRef]

9. Grootaert, C.; Van Bastelaer, T. Understanding and Measuring Social Capital: A Synthesis of Findings and Recommendations from the Social Capital Initiative; World Bank: Washington, DC, USA, 2002.

10. Saz-Gil, I.; Bretos, I.; Díaz-Foncea, M. Cooperatives and Social Capital: A Narrative Literature. Review and Directions for Future Research. Sustainability 2021, 13, 534. [CrossRef]

11. Arrow, J.K. Observations on Social Capital. In Social Capital a Multifaceted Perspective; Dasgupta, P., Serageldin, I., Eds.; The World Bank: Washington, DC, USA, 2000; pp. 3-5.

12. Solow, R.M. Notes on Social Capital and Economic Performance. In Social Capital a Multifaceted Perspective; Dasgupta, P., Serageldin, I., Eds.; The World Bank: Washington, DC, USA, 2000; pp. 6-12.

13. Lundqvist, L.J. 'Nested enterprises'? Spatial dimensions of ecological governance. In Sweden and Ecological Governance; Manchester University Press: Manchester, UK, 2018. [CrossRef]

14. Coase, R. The problem of social cost. Law Econ. 1960, 3, 1-44. Available online: http://www.jstor.com/stable/724810 (accessed on 2 November 2021). [CrossRef]

15. Capra, F.; Mattei, U. The Ecology of Law: Toward a Legal System in Tune with Nature and Community; Berrett-Koehler Publishers: Oakland, CA, USA, 2015.

16. Bertolini, P.; Giovannetti, E. L'evoluzione del Sistema Locale del Parmigiano Reggiano. DEMB Working Paper Series n. 178. 2020. Available online: https:/ /iris.unimore.it/retrieve/handle/11380/1212582/283366/0178.pdf (accessed on 2 November 2021).

17. Giovannetti, E.; Bertolini, P. L'assetto Strutturale e le Performance dei Caseifici del Settore del Parmigiano Reggiano: Una Valutazione Microeconomica. DEMB Working Paper Series n. 180. 2020. Available online: https://iris.unimore.it/retrieve/ handle/11380/1226085/312946/0180.pdf (accessed on 2 November 2021).

18. Hardin, G. The Tragedy of the Commons. Science 1968, 162, 1243-1248. [CrossRef] [PubMed]

19. Ostrom, E. Beyond Markets and States: Polycentric Governance of Complex Economic Systems. Am. Ec. R. 2010, 100, 641-672. [CrossRef]

20. Ostrom, E. A diagnostic approach for going beyond panaceas. Proc. Natl. Acad. Sci. USA 2007, 104, 39. [CrossRef]

21. Ostrom, E. Social Capital: A Fad or a Fundamental Concept? In Social Capital a Multifaceted Perspective; Dasgupta, P., Serageldin, I., Eds.; The World Bank: Washington, DC, USA, 2000; pp. 172-214.

22. Ostrom, E. Governing the Commons. The Evolution of Institutions for Collective Action; Cambridge Un. Press: Cambridge, UK, 1990.

23. Anderies, J.; Janssen, M.; Ostrom, E. A Framework to Analyze the Robustness of Social-ecological Systems from an Institutional Perspective. Resil. Alliance 2004. Available online: https://www.ecologyandsociety.org/vol9/iss1/art18/ (accessed on 2 November 2021). [CrossRef]

24. Poteete, A.R.; Janssen, M.A.; Ostrom, E. Working Together: Collective Action, The Commons, and Multiple Methods in Practice; Princeton Un. Pr.: Princeton, NJ, USA, 2010.

25. Georgescu-Roegen, N. Entropy Law and Economic Process; Harvard Un. Press: Cambridge MA, USA, 1971.

26. Nourse, E. The Economic Philosophy of Cooperation. Am. Ec. R. 1922, 12, 577-597.

27. Birchall, J. The International Co-Operative Movement; Manchester Un. Press: Manchester, UK, 1997.

28. ICA International Coop Alliance. Available online: https://www.ica.coop/en/cooperatives/cooperative-identity (accessed on 2 November 2021).

29. Bauer, C.M.; Guzmán, C.; Santos, F.J. Social capital as a distinctive feature of Social Economy firms. Int. Entrep. Manag. J. 2012, 8, 437-448. [CrossRef]

30. Borzaga, C.; Sforzi, J. Social capital, cooperatives and social enterprises. In Social Capital and Economics; Routledge: London, UK, 2014; pp. 193-214.

31. United Nations Sustainable Development-17 Goals to Transform Our World. Available online: https://www.un.org/ sustainabledevelopment/ (accessed on 2 November 2021).

32. Gupta, J.; Vegelin, C. Sustainable development goals and inclusive development. Int. Environ. Agreem. 2016, 16, 433-448. [CrossRef] 
33. Putnam, R.; Leonardi, R.; Nannetti, R. Making Democracy Work: Civic Traditions in Modern Italy; Princeton University Press: Princeton, NJ, USA, 1993.

34. Pagliacci, F.; Zavalloni, M.; Raggi, M.; Viaggi, D. Coordination in the agri-food sector: The role of social capital and remoteness in the emergence of Italian network contracts. J. Rural Stud. 2020, 77, 93-104. [CrossRef]

35. Menard, C. Cooperatives: Hierarchies or Hybrids? In Vertical Markets and Cooperative Hierarchies; Karantininis, K., Nilsson, J., Eds.; Springer Academic Publishers: Berlin/Heidelberg, Germany, 2006. Available online: https://www.researchgate.net/publication/ 225231064_Cooperatives_Hierarchies_or_Hybrids (accessed on 2 November 2021). [CrossRef]

36. Scarpato, D.; Civero, G.; Rusciano, V.; Risitano, M. Sustainable strategies and corporate social responsibility in the Italian fisheries companies. Corp. Soc. Responsib. Environ. Manag. 2020, 27, 2983-2990. [CrossRef]

37. Scarpato, D.; Civero, G.; Rusciano, V. Social and Ecological High Influential Factors in Community Gardens Innovation: An Empirical Survey in Italy. Sustainability 2020, 12, 4653. [CrossRef]

38. Hogeland, J.A. The Economic Culture of U.S. Agricultural Cooperatives. Cult. Agric. 2006, 28, 67-79. [CrossRef]

39. Bertolini, P.; Pagliacci, F. Il terremoto del 2012 in Emilia: Specificità del settore agro-alimentare e ruolo della cooperazione nell'emergenza. Agriregionieuropa 2016, 12, 44. Available online: https://agriregionieuropa.univpm.it/it/print/9553 (accessed on 2 November 2021).

40. U.S. Department of Agriculture, Rural Business and Cooperative Development Service. Understanding Capper-Volstead; Cooperative Information Report 35, Reprinted April, 1995; 1985. Available online: https:/ / www.rd.usda.gov/files/cir35.pdf (accessed on 2 November 2021).

41. Bureau Van Dijk-AIDA Archive. Available online: https://www.bvdinfo.com/it-it/le-nostre-soluzioni/dati/nazionali/aida (accessed on 2 November 2021).

42. OCQPR Organismo Controllo Qualità Produzioni Regolamentate (Agency for the Quality Control of Regulated Productions). Available online: https: / / www.ocqpr.it/ (accessed on 2 November 2021).

43. Parmigian Cheese Consortium. Available online: https://www.parmigianoreggiano.com/ (accessed on 2 November 2021). 